Quim. Nova, Vol. 30, No. 7, 1750-1753, 2007

\title{
EMPREGO DE PLANEJAMENTO FATORIAL NO DESENVOLVIMENTO DE UMA METODOLOGIA PARA EXTRAÇÃO DE ZINCO DE RESÍDUOS GALVÂNICOS
}

\author{
Samantha Olivier*, Valdinete Lins da Silva e Maurício da Motta \\ Departamento de Engenharia Química, Universidade Federal de Pernambuco, Av. Prof. Arthur de Sá, s/n, \\ 50740-521 Recife - PE, Brasil \\ José Edson da Silva \\ Departamento de Química Fundamental, Universidade Federal de Pernambuco, 50740-540 Recife - PE, Brasil
}

Recebido em 2/10/06; aceito em 18/1/07; publicado na web em 25/9/07

\begin{abstract}
USE OF FACTORIAL PLANNING IN DEVELOPING A METHODOLOGY FOR GALVANIC ZINC RESIDUE EXTRACTION. The plating process generates solid waste rich in heavy metals and aiming to reduce environmental impact of such waste, this work suggests a methodology for zinc reduction, through a $2^{4}$ factorial planning, studying the influence of the following variables: acid concentration $(15,20$ or $30 \% \mathrm{v} / \mathrm{v})$, acid type (sulfuric or hydrochloric), acid volume (15, 20 or $25 \mathrm{~mL}$ ) and extraction time (12, 24 or $36 \mathrm{~h})$. Through this methodology it is possible to establish the optimal conditions ( $15 \mathrm{~mL}$ of a $30 \%$ hydrochloric acid concentration during $12 \mathrm{~h}$ ) to get a $100 \%$ efficiency in zinc extraction.
\end{abstract}

Keywords: electroplating; galvanic sludge; zinc.

\section{INTRODUÇÃO}

O homem é hoje um poderoso agente de alteração dos ciclos naturais, visto que as principais conquistas da humanidade introduziram perturbações no equilíbrio da biosfera, alterando ecossistemas vitais. O desenvolvimento tecnológico, com a criação de novas substâncias e produtos, muitas vezes descartáveis, vem contribuindo para uma aceleração dessa degradação. Em decorrência disto, jamais alguma civilização teve em âmbito planetário o poder desestabilizador que tem a sociedade contemporânea. As mudanças ambientais em curso estão concentradas em poucas décadas, possuem escopo global e estão profundamente relacionadas com o comportamento humano ${ }^{1}$.

Podemos citar diversos fatores que contribuem para a agressão ambiental na sociedade contemporânea, dentre os quais o esgotamento dos recursos naturais, um conjunto de valores e comportamentos centrados na expansão do consumo material e sistemas produtivos que utilizam processos de produção poluentes ${ }^{1}$ que, aliados ao crescimento populacional acelerado, têm contribuído para o aumento da produção de resíduos que precisam ser descartados para dar lugar a novos bens, formando um ciclo de agressão ao ambiente ${ }^{2}$.

O destino dos resíduos sólidos é uma questão de saúde pública e considera-se sua disposição como a etapa final dos processos industriais, em que os produtos mobilizados pelo homem para a satisfação de diversas necessidades são devolvidos ao ambiente. A área física que serve como depósito, seja o vazadouro a céu aberto, aterro controlado ou sanitário, não pode ser considerada como o ponto final para muitas substâncias contidas nos resíduos sólidos, uma vez que estas podem atingir solo, água ou ar, sendo transportadas para outras áreas podendo, até mesmo, entrar na cadeia alimentar e atingir o homem³ .

Várias indústrias têm gerado grandes quantidades de poluentes que, em muitos casos, têm sido descartados no meio ambiente sem nenhum tipo de tratamento ${ }^{4}$. A principal razão deste comportamento consiste na falta de investimentos na busca de técnicas para o tratamento dos efluentes industriais.

*e-mail: sam.olivier@bol.com.br
Efluentes saturados com sais de metais pesados são inerentes a vários processos industriais, como fabricação de certos pigmentos, recobrimento de peças metálicas etc ${ }^{5}$. Entre os inúmeros processos classificados como de elevado potencial poluidor pela norma NBR 10004/2004 está a galvanização, técnica que tem como base a deposição de cátions metálicos em superfícies, por meio de corrente elétrica (eletrólise), fornecendo proteção contra oxidação e/ou conferindo valor estético. A composição do efluente varia conforme os metais presentes durante a deposição ${ }^{6}$. Chumbo, cromo, cobre, ferro, mercúrio, níquel, selênio e zinco são os metais pesados mais freqüentemente encontrados em efluentes industriais ${ }^{7}$.

A zincagem é muito empregada por ser de fácil aplicação, resultando em produtos mais baratos que os obtidos por outros tipos de revestimentos similares. Para aumentar a resistência à corrosão branca e à abrasão da camada de zinco e melhorar o seu aspecto visual, realiza-se a cromatização após a zincagem. A camada formada tem diferentes colorações, dependendo da espessura da mesma. Somente 30 a $40 \%$ de todo o metal utilizado no processo de eletrodeposição são efetivamente consumidos ${ }^{8}$.

Os resíduos líquidos contendo zinco, provenientes de vários processos das linhas de produção são responsáveis pela maior parte do $\mathrm{Zn}^{+2}$ encontrado em águas residuárias galvânicas ${ }^{9}$. Técnicas como filtração, floculação, osmose reversa ${ }^{10}$, precipitação química ou coagulação, troca iônica e eletrodeposição já estão disponíveis para algumas indústrias ${ }^{11}$. A remoção e recuperação dos metais pesados presentes em efluentes industriais, após o tratamento destes, têm recebido grande atenção nos últimos anos ${ }^{12}$.

Um dos métodos mais utilizados para tratamento destes efluentes é a coagulação, por seu custo e facilidade operacional. No entanto, este método apresenta uma eficiência mediana na remoção dos metais pesados e gera uma grande quantidade de resíduos sólidos conhecidos como lodo ou borra da estação de tratamento de efluentes. Os resíduos contaminados com metais, principalmente metais pesados, capazes de poluir o solo e as águas subterrâneas ${ }^{13}$, podem ser estabilizados de diferentes maneiras. Uma metodologia muito popular é a agregação do resíduo em cimento ou outros materiais inertes ${ }^{14,15}$. A solidificação deste material, no entanto, torna-se muito 
volumosa e o procedimento requer grandes espaços ${ }^{16}$

Outro método consiste na remoção dos metais pesados tóxicos por métodos como a extração iônica ${ }^{17,18}$, eletroquímica ${ }^{19}$, quími$\mathrm{ca}^{20}$ ou biológica ${ }^{21,22}$. Utilizando-se um método químico ou biológico, a remoção seletiva torna o resíduo não perigoso e possibilita a concentração e reciclagem dos metais ${ }^{23}$.

Apesar dos resíduos provenientes de operações de eletrodeposição serem considerados tóxicos ${ }^{24}$ e estarem incluídos na Classe I de resíduos sólidos, a qual pertencem todos os resíduos considerados perigosos para a saúde pública, o método mais comumente empregado atualmente para a sua destinação em países em desenvolvimento, como o Brasil, é sua disposição em aterros sanitários industriais ${ }^{25}$.

Quando manuseados ou dispostos de forma inadequada estes resíduos contribuem para aumento da mortalidade ou da incidência de doenças, além de apresentarem efeitos adversos ao meio ambiente ${ }^{26}$.

Por conta disto, um tratamento adequado para remoção dos metais pesados se faz necessário. O uso de planejamentos experimentais, em especial os planejamentos fatoriais, permite o estudo e a representação de um processo ou sistema utilizando-se um modelo matemático obtido através de técnicas estatísticas. De posse do modelo, é possível então a construção de superfícies de resposta que servem para uma análise mais efetiva dos efeitos das variáveis envolvidas no processo e, também, para a otimização do mesmo.

O planejamento experimental relaciona as variáveis em estudo de maneira sistemática, proporcionando a obtenção das respostas desejadas com um mínimo de tempo, fator imprescindível para o bom andamento da pesquisa.

Dentre os planejamentos experimentais existentes destacam-se os planejamentos fatoriais, os quais são amplamente utilizados em experimentos em que é necessário estudar os efeitos de interação dos fatores sobre a resposta. Como o próprio nome indica, essa técnica exige um planejamento prévio dos experimentos, que inclui a escolha das variáveis (fatores) e dos valores que estas assumirão nas corridas experimentais (níveis).

Para este trabalho, que tem como objetivo propor uma metodologia para remoção de zinco de resíduos industriais provenientes da galvanização, optou-se por um planejamento do tipo BoxBehnken $^{27}$, que reduz significativamente o número de experimentos necessários. Este método consiste basicamente no planejamento fatorial clássico de dois níveis $\left(2^{\mathrm{k}}\right)$ acrescido de pontos centrais que permitem a estimativa dos coeficientes de segunda ordem.

\section{PARTE EXPERIMENTAL}

\section{Descrição sumária das amostras}

O material utilizado nos experimentos foi obtido em uma indústria galvânica especializada em peças automotivas, localizada no Estado de Pernambuco. Vários produtos produzidos nessa indústria recebem um revestimento à base de zinco, visando a proteção contra corrosão. O método de tratamento das águas residuárias resultantes deste processo é físico-químico, precisamente a coagulação, que gera, conseqüentemente, um resíduo sólido contaminado com zinco.

O resíduo constitui um material relativamente úmido, de aspecto pastoso e compacto (Figura 1). Possui coloração marrom, não contém odor e pode facilmente ser confundido com substrato argiloso ou material orgânico, se encontrado livre no meio ambiente.

\section{Tratamento do resíduo contendo zinco}

O material foi acondicionado em recipientes de vidro e seco em estufa a $60{ }^{\circ} \mathrm{C}$ durante $8 \mathrm{~h}$. Após resfriamento, pesou-se $5 \mathrm{~g}$ do material moído em béquer de $100 \mathrm{~mL}$, acrescentou-se o ácido e a

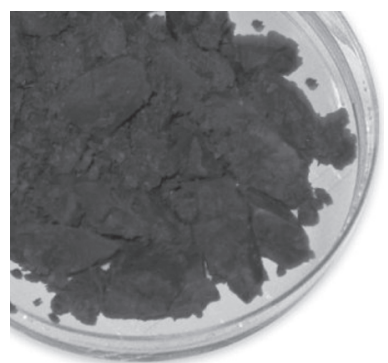

Figura 1. Resíduo proveniente da galvanização

mistura foi deixada em repouso, em temperatura ambiente, de acordo com as condições estipuladas pelo planejamento experimental. Depois de decorrido o tempo referente a cada ensaio, as amostras foram filtradas em papel de filtro qualitativo, diluídas com água destilada e o teor de zinco foi determinado utilizando-se um espectrômetro de absorção atômica em chama 220 FS da Varian.

A eficiência da remoção de zinco do resíduo foi avaliada através da aplicação de um planejamento fatorial $2^{4}$, acrescido de um ponto central em triplicata para cada tipo de ácido (Tabela 1). Dessa forma foi estudada a influência das variáveis: concentração de ácido $(10,20$ ou $30 \% \mathrm{v} / \mathrm{v})$, tipo de ácido aplicado (sulfúrico ou clorídrico), volume de ácido $(15,20$ ou $25 \mathrm{~mL})$ e tempo de extração $(12,24$ ou 36 h). A resposta que se desejou otimizar foi a eficiência da retirada de zinco do resíduo.

Tabela 1. Planejamento fatorial

\begin{tabular}{lcccc}
\hline Ensaio & $\begin{array}{c}\text { Concentração } \\
(\mathrm{M})\end{array}$ & $\begin{array}{c}\text { Tipo de } \\
\text { ácido }\end{array}$ & $\begin{array}{c}\text { Volume } \\
(\mathrm{mL})\end{array}$ & $\begin{array}{c}\text { Tempo } \\
(\mathrm{h})\end{array}$ \\
\hline 1 & 15 & $\mathrm{H}_{2} \mathrm{SO}_{4}$ & 15 & 12 \\
2 & 25 & $\mathrm{H}_{2} \mathrm{SO}_{4}$ & 15 & 12 \\
3 & 15 & $\mathrm{HCl}$ & 15 & 12 \\
4 & 25 & $\mathrm{HCl}$ & 15 & 12 \\
5 & 15 & $\mathrm{H}_{2} \mathrm{SO}_{4}$ & 25 & 12 \\
6 & 25 & $\mathrm{H}_{2} \mathrm{SO}_{4}$ & 25 & 12 \\
7 & 15 & $\mathrm{HCl}$ & 25 & 12 \\
8 & 25 & $\mathrm{HCl}_{2}$ & 25 & 12 \\
9 & 15 & $\mathrm{H}_{2} \mathrm{SO}_{4}$ & 15 & 36 \\
10 & 25 & $\mathrm{H}_{2} \mathrm{SO}_{4}$ & 15 & 36 \\
11 & 15 & $\mathrm{HCl}$ & 15 & 36 \\
12 & 25 & $\mathrm{HCl}_{2}$ & 15 & 36 \\
13 & 15 & $\mathrm{H}_{2} \mathrm{SO}_{4}$ & 25 & 36 \\
14 & 25 & $\mathrm{H}_{2} \mathrm{SO}_{4}$ & 25 & 36 \\
15 & 15 & $\mathrm{HCl}_{2}$ & 25 & 36 \\
16 & 25 & $\mathrm{HCl}_{2}$ & 25 & 36 \\
17 & 20 & $\mathrm{H}_{2} \mathrm{SO}_{4}$ & 20 & 24 \\
18 & 20 & $\mathrm{H}_{2} \mathrm{SO}_{4}$ & 20 & 24 \\
19 & 20 & $\mathrm{H}_{2} \mathrm{SO}_{4}$ & 20 & 24 \\
20 & 20 & $\mathrm{HCl}_{2}$ & 20 & 24 \\
21 & 20 & $\mathrm{HCl}_{22}$ & 20 & 24 \\
22 & 20 & $\mathrm{HCl}$ & 20 & 24 \\
\hline
\end{tabular}

Para avaliar a eficácia da metodologia desenvolvida, foi realizada uma digestão nitro-perclórica ${ }^{28}$, visto que através desta metodologia é possível dissolver todo o resíduo, no entanto, esta via apresenta o inconveniente do manuseio e alto custo dos ácidos utilizados. Os resultados desta digestão foram comparados com a metodologia proposta.

Após a aquisição dos dados, através de espectrômetro de absorção atômica em chama, relativos às concentrações de Zn tratado com ácido clorídrico ou sulfúrico, através do software Statistica 6.0 $0^{29}$, foram realizadas análises baseadas nos efeitos do planejamento 
fatorial e calculadas em um nível de $95 \%$ de confiança, buscandose os efeitos significativos dos tratamentos.

\section{RESULTADOS E DISCUSSÃO}

\section{Parâmetros físico-químicos}

Ao término dos ensaios observou-se que com ácido sulfúrico houve formação de um gel de cor esverdeada (Figura 2a) enquanto que com o ácido clorídrico se formou um resíduo de cor marrom e o líquido sobrenadante tornou-se amarelo (Figura 2b).

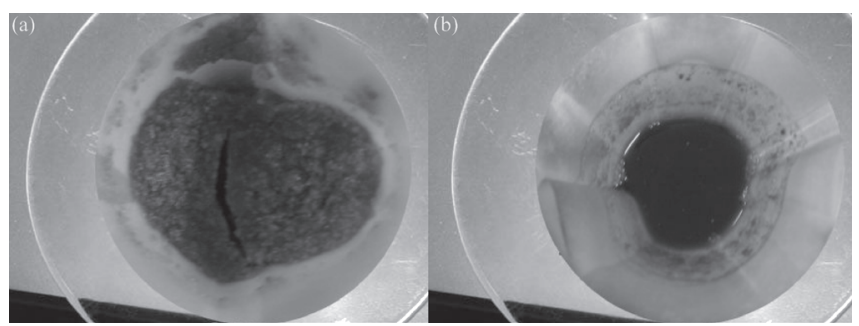

Figura 2. Resíduo após tratamento com ácido sulfúrico (a) e com ácido clorídrico (b)

A concentração de zinco obtida pela metodologia da digestão nitro-perclórica foi de $79,8 \mathrm{mg} \mathrm{L}^{-1}$. Os resultados da metodologia propostas variaram de 38,2 a $79,8 \mathrm{mg} \mathrm{L}^{-1}$, indicando uma eficiência de extração de 47,9 a $100 \%$.

\section{Planejamento fatorial}

Os efeitos das variáveis sobre a eficiência de remoção de zinco, obtidos a partir do planejamento fatorial realizado, estão sumarizados na Tabela 2.

Tabela 2. Efeitos do planejamento fatorial $2^{4}$, calculados com $95 \%$ de confiança

\begin{tabular}{|c|c|c|}
\hline & & Estimativa \\
\hline \multirow[t]{2}{*}{$\bar{M}$} & Média global & $85,8 \pm 0,6$ \\
\hline & Efeitos principais & \\
\hline$\overline{\mathrm{CA}}$ & Concentração do ácido (\%) & $19,0 \pm 1,3$ \\
\hline $\mathrm{TA}$ & Tipo de ácido & $-7,5 \pm 1,3$ \\
\hline VA & Volume de ácido (mL) & $2,5 \pm 1,3$ \\
\hline \multirow[t]{9}{*}{$\mathrm{T}$} & Tempo de contato & $-5,0 \pm 1,3$ \\
\hline & Efeito de interação de dois fatores & \\
\hline & $\mathrm{CA} \times \mathrm{TA}$ & $12,4 \pm 1,3$ \\
\hline & $\mathrm{CA} \times \mathrm{VA}$ & $0,1 \pm 1,3$ \\
\hline & $\mathrm{CA} \times \mathrm{T}$ & $-5,4 \pm 1,3$ \\
\hline & TA $x$ VA & $6,6 \pm 1,3$ \\
\hline & $\mathrm{TA} \times \mathrm{T}$ & $14,4 \pm 1,3$ \\
\hline & VA $x \mathrm{~T}$ & $-1,2 \pm 1,3$ \\
\hline & Efeito de interação de três fatores & \\
\hline 123 & CA $x$ TA $x$ VA & $-1,3 \pm 1,3$ \\
\hline 124 & $\mathrm{CA} \times \mathrm{TA} \times \mathrm{T}$ & $-3,6 \pm 1,3$ \\
\hline 134 & $\mathrm{CA} \times \mathrm{VA} \times \mathrm{T}$ & $-2,5 \pm 1,3$ \\
\hline \multirow[t]{4}{*}{234} & TA $x$ VA $x \mathrm{~T}$ & $9,9 \pm 1,3$ \\
\hline & Efeito de interação de quatro fatores & \\
\hline & CA $x$ TA $x$ VA $x T$ & $0,6 \pm 1,3$ \\
\hline & $\mathrm{t} \times \mathrm{s}$ & 5,5939 \\
\hline
\end{tabular}

Calculando-se os efeitos do planejamento fatorial em um nível de $95 \%$ de confiança, concluiu-se que serão significativos apenas os efeitos que excederem o produto do t de Student (para 2 graus de liberdade) pelo erro padrão dos efeitos 4,303 x 1,3 = 5,6.

De acordo com os resultados da Tabela 2, pode-se observar que entre os efeitos principais apenas a concentração e o tipo de ácido foram significativos. Elevar a concentração do ácido de 10 para $30 \%$ provoca um aumento médio de $19 \%$ na extração do zinco do resíduo. Por outro lado, mudar o tipo de ácido de $\mathrm{H}_{2} \mathrm{SO}_{4}$ para $\mathrm{HCl}$ prejudica o método, diminuindo em 7,5\% o teor de zinco extraído. Entretanto, verifica-se que essas duas variáveis interagem de forma sinergética, ou seja, o aumento simultâneo dos níveis desses dois fatores, isto é, mudar a CA de 10 para $30 \%$ e TA de $\mathrm{H}_{2} \mathrm{SO}_{4}$ pra $\mathrm{HCl}$ melhora a extração em média $12 \%$.

Embora o efeito do VA isoladamente não seja significativo, este fator interage com a variável TA também de forma sinergética, favorecendo a extração em aproximadamente 6,6\%. Isso significa que se o volume de ácido for aumentado, deve-se mudar para $\mathrm{HCl}$ ao mesmo tempo.

O tempo de extração não interferiu de forma significativa, mas sua interação com o tipo de ácido indica que se forem usados tempos de contato muito grandes ( $36 \mathrm{~h}$ ) deve-se utilizar $\mathrm{HCl}$, o que aumenta em média $14,4 \%$ o rendimento.

Entre os efeitos da interação de três fatores apenas a interação TA x VA x T demonstrou ser significativa. Nesse caso, ao aumentar essas três variáveis simultaneamente eleva-se a extração de zinco em cerca de $9,9 \%$.

Observando-se os resultados dos ensaios constata-se que em muitas situações a extração de zinco foi próxima a 100\%. Analisando-se do ponto de vista de eficiência e tempo de tratamento, a situação representada pelo ensaio $4(\mathrm{CA}=30 \%, \mathrm{TA}=\mathrm{HCl}, \mathrm{VA}=15 \mathrm{~mL}, \mathrm{~T}=12$ $\mathrm{h}, \eta=100 \%$ ) é a recomendada como procedimento padrão a ser adotado. Além disso, esta condição é mais viável economicamente, pois utiliza um ácido de menor custo e um menor volume do mesmo.

\section{CONCLUSÃO}

Este trabalho apontou alternativas para extração de zinco de resíduos galvânicos, com uma diminuição efetiva do número de experimentos, tornou possível a constatação de que ambos os ácidos são capazes de extrair zinco de resíduos industriais galvânicos e, através do planejamento fatorial, foi possível estabelecer condições para eficiência e baixo custo dos tratamentos, sendo a condição de trabalho adotada (15 mL de ácido clorídrico a 30\% durante $12 \mathrm{~h}$ ) a menos agressiva para o meio ambiente quando comparada aos tratamentos com ácido sulfúrico; a de melhor custo visando sua aplicação diretamente nas indústrias geradoras do resíduo e, com eficiência de extração do zinco de até $100 \%$.

\section{AGRADECIMENTOS}

Ao apoio financeiro da Coordenação de Aperfeiçoamento de Pessoal de Nível Superior (CAPES) e ao Mestrado em Gestão e Políticas Ambientais da Universidade Federal de Pernambuco (UFPE).

\section{REFERÊNCIAS}

1. Camargo, A. L. B.; Desenvolvimento sustentável, Papirus: Campinas, 2003.

2. Costley, S. C.; Wallis, F. M.; Water Res. 2001, 35, 3715.

3. Lee, I. H.; Kuan, Y.; Chern, J.; J. Hazard. Mater, 2006, 183, 3.

4. Aderhold, D.; Williams, C. J.; Edyvean, R. G. J.; Bioresour. Technol. 1996, 58,1 .

5. Mohammadi, T.; Moheb, A.; Sadrzadeh, M.; Razmi, A.; Sep. Purif. Technol. 
$\mathbf{2 0 0 5}, 41,73$

6. Brett, A. M.O.; Brett, C. M. A.; Electroquímica: princípios, métodos e aplicações, Almedina: Coimbra, 1996.

7. Chang, E. E.; Chiang, P. C.; Lu, P. H.; Ko, Y. W.; Chemosphere 2001, 45, 91.

8. Adhoum, N.; Monser, L.; Bellakhal, N.; Belgaied, J.; J. Hazard. Mater 2004, 112, 207.

9. Grebenyuk, V. D.; Sorokin, G. V.; Verbich, S. V.; Zhiginas, L. H.; Linkov, V. M.; Linkov, N. A.; Smit J. J.; Water Res. 1996, 22, 381.

10. Zhao, M.; Duncan, J. R.; van Hille, R. P.; Water Res. 1999, 33, 1516.

11. Horsfall Jr., M.; Abia, A. A.; Water Res. 2003, 37, 4913.

12. Kargi, F.; Cikla, S.; Enzyme Microb. Technol. 2006, 38, 705.

13. Flyhammar, P.; Sci. Total Environ. 1997, 198, 123.

14. Jain, N.; Minocha, A. K.; Verma, C. L.; Construction and Building Mater. 2003, 17, 77.

15. Lee, I. H.; Wang, Y; Chern, J.; J. Hazard. Mater. 2005, 123, 112.

16. Cioffi, R.; Lavorgna, M.; Santoro, L.; J. Hazard. Mater. 2002, 89, 165.

17. Villiers, P. G. R.; van Deventer, J. S. J.; Lorenzen, L.; Miner. Eng. 1995, 8, 1309.

18. Parkpian, P.; Leong, S. T.; Laortanakul, P.; Poonpolwatanaporn, P.; J. Environ. Sci. Health 2002, 37, 1855.
19. Zagury, G. J.; Dartiguenave, Y.; Setier, J. C.; J. Environ. Eng. 1999, 125, 972.

20. Neyens, E.; Baeyens, J.; Weemaes, M.; De Heyder, B.; J. Hazard. Mater 2003, 98, 275.

21. Xiang, L.; Chan, L. C.; Wong, J. W. C.; Chemosphere 2000, 40, 283.

22. Shanableh, A.; Omar, M.; Soil Sediment Contam. 2003, 12, 565.

23. Jha, M. K.; Kumar, V.; Singh, R. J.; Resour. Conserv. Recycl. 2001, 33, 1.

24. ASTM;. Standard Test Method for Shake Extraction of Solid Waste with Water, ASTM D3987-85, 1981, p. 24-27.

25. Braga, B.; Hespanhol, I.; Conejo, J. G.; Barros, M. T.; Spencer, M.; Porto, M.; Nucci, N.; Juliano, N.; Eiger, S.; Introdução à engenharia ambiental, Prentice Hall: São Paulo, 2002

26. ABNT. Associação Brasileira de Normas Técnicas;. NBR 10004, Resíduos sólidos, 2004.

27. Box, G. E. P.; Behnken, D. W.; Technometrics 1960, v. 2.

28. Malavolta, E.; Manual de química agrícola, adubos e adubação, $3^{\mathrm{a}}$ ed., Agronômica Ceres: São Paulo, 1981.

29. Statsoft, Inc; Statistica: data analysis software system, version 6.0, 2001, CD/ROM. 